\title{
Teorías y líneas de investigación en el sistema de franquicia: una revisión desde los años 60 hasta 2009
}

\section{Theories and research lines regarding the franchise system: a review from the 60's to 2009}

\author{
VerónICA BAENa GRACIÁn \\ Universidad Europea de Madrid
}

Recibido el 2 de abril de 2009, aceptado el 23 de febrero de 2010

$\mathrm{N}^{\circ}$ de clasificación JEL: M10

DOI: $10.5295 / \mathrm{cdg} .100155 \mathrm{vb}$

Reseña Bibliográfica: BAENA GRACIÁ, V. (2010): “Teorías y líneas de investigación en el sistema de la franquicia: una revisión desde los años 60 hasta 2009"; Cuadernos de Gestión, Vol. 10. № 2, pp. 43-66. DOI: $10.5295 / \mathrm{cdg} .100155 \mathrm{vb}$

\begin{abstract}
Resumen:
Diversos trabajos han analizado el sistema de franquicia y señalado las líneas principales de investigación con respecto a los trabajos científicos publicados hasta el momento (Elango y Fried, 1997; Díez de Castro y Rondán, 2004). El presente artículo pretende continuar este proceso y además, identificar las teorías aplicadas al estudiar el sistema de franquicia -teoría de la agencia, teoría de la escasez de recursos, teoría de la extensión del riesgo, teoría contractual, teoría de los costes de transacción y teoría de las señales-, explicando las contribuciones que realiza cada una de ellas a la literatura. Seguidamente, se identifican cuatro líneas de investigación predominantes junto con los principales trabajos publicados en el sistema de franquicia, prestando especial atención a los estudios elaborados por investigadores españoles bajo la forma de artículos, actas de congresos, monografías, capítulos de libro y tesis doctorales. Con ello, pretendemos ofrecer una visión amplia del estado de la literatura desde los años 60 hasta nuestros días.
\end{abstract}

Palabras clave:

Sistema de Franquicia, Franquiciador, Franquiciado, Revisión de Literatura.

\begin{abstract}
:
Many works have analyzed franchising and identified the major research lines regarding the scientific works published until that moment (Elango and Fried, 1997; Díez de Castro and Rondán, 2004). The present paper tries to follow this process. Moreover, it is identified the theories used by researchers to study franchising -agency theory, resource scarcity theory, risk extension theory, contractual theory, transaction cost theory, as well as signaling theory-, and explained its contributions to the literature. Subsequently, four research lines are highlighted in conjunction with main literature about the topic, and emphasized those studies developed by Spanish researchers under the form of papers, conference proceedings, books, book's chapters, as well as dissertations. In doing so, we attempt to offer a whole vision about franchising literature from the 60s up to date.
\end{abstract}

Keywords:

Franchising System, Franchisor, Franchisee, Literature Review.

\footnotetext{
${ }^{1}$ Universidad Europea de Madrid. Departamento de Empresa. C/ Tajo, s/n. Urb. El Bosque 28670 - Villaviciosa de Odón (Madrid). E-mail: veronica.baena@uem.es
} 


\section{INTRODUCCIÓN}

La franquicia es un modelo de desarrollo empresarial que ha alcanzado un elevado grado de madurez en el mundo. Esto se debe a que resulta una forma atractiva de organización corporativa para las empresas que desean expandirse rápidamente con una inversión baja de capital, y un control adecuado de sus procesos de distribución (Erramilli, Agarwal y Dev, 2002). Cierto es que la opción de crecer en franquicia es una entre muchas otras alternativas de desarrollo, pero no lo es menos que esta fórmula encuentra en sus supuestos de partida, así como en la perfecta adecuación de éstos a las empresas y mercados actuales, la verdadera razón de su espectacular progresión.

De este modo, la franquicia representa hoy en día, el que quizás ya sea el sistema de expansión empresarial más empleado y desarrollado de las economías modernas, especialmente en ciertos sectores, tales como el comercio minorista o la hostelería. Por ello, cualquier empresa que goce de un adecuado posicionamiento en su entorno de actuación y que cuente con ciertas perspectivas de crecimiento, no puede dejar de ver en la franquicia una de las alternativas más rentables y eficaces para la consecución de todo objetivo relativo a la cobertura de nuevos mercados (Michael, 2003). En este sentido, algunas cifras publicadas en 2009 por la International Franchise Association ${ }^{l}$ señalan que en países como EE.UU., donde el comercio minorista tiene una trayectoria de estabilidad amplia, el 40 por ciento de los comercios independientes sobreviven al segundo ejercicio de apertura. Esta cifra desciende 10 puntos (30\%) tras el tercer ejercicio. Frente a esta estadística, los comercios en franquicia que sobreviven a los primeros ejercicios son casi el 95\% mientras que un año después, el porcentaje es prácticamente el mismo. No en vano, el sistema de franquicia norteamericano es el mercado más competitivo del mundo y el primero en número de empresas franquiciadoras, con un total de 1.500 cadenas y 767.483 establecimientos franquiciados, a través de los cuales se factura anualmente más de 165.000 millones de euros (Tormo \& Asociados, 2008).

En relación al caso español, el siglo XX ha sido un fiel testigo de la enorme evolución del sistema de franquicia en España, si bien es cierto que fue en la década de los 80 cuando la franquicia inicia su despegue en nuestro país (Rondán, Navarro y Díez de Castro, 2007). En la actualidad, el sistema de franquicia continúa registrando en España una tendencia creciente en sus niveles de facturación. Así pues, de los 13.990 millones de euros ingresados por ventas en 2002, durante los años 2004, 2005, 2006 y 2007 se han experimentado tasas de crecimiento interanual superiores al 9 por ciento $(9,3 \%, 9,4 \%, 9,5 \%, y 11,4 \%$, respectivamente). $\mathrm{Al}$ cierre del ejercicio de 2008, las cifras se situaron en los 20.869 millones de euros y representaron un crecimiento del 1 por ciento respecto de los datos registrados en 2007. Un dato que se traduce en que, de media, cada establecimiento facturó en torno a los 302.000 euros $^{2}$.

Por otra parte, durante el año 2008 se crearon 146 nuevas cadenas franquiciadoras en España aunque el cómputo de crecimiento neto fue algo menor, -en concreto 17 enseñas-, ya que si bien se han producido muchas aperturas de nuevos negocios (principalmente del sector hostelero, retail y servicios), éstas han quedado compensadas por los cierres produ-

\footnotetext{
${ }^{1}$ International Franchise Association - 2009 Economic Outlook Report. Disponible en: http://www.franchise.org/ IndustrySecondary.aspx?id=4284 Última fecha de acceso: 3/12/2009.

2 «Situación actual de la franquicia en España». Informe publicado en 2009 por la consultora Tormo \& Asociados. Disponible en http://www.tormo-asociados.es/docs/Avance.pdf. Última fecha de acceso: 11 de diciembre de 2009.
} 
cidos en el sector inmobiliario y financiero. Por lo tanto, en la actualidad operan en España 985 cadenas franquiciadoras (de origen nacional y extranjero), las cuales agrupan 73.600 establecimientos operativos -entre unidades propias y franquiciadas- lo que implica una media de casi 75 establecimientos por cadena. En resumen, el sistema de franquicia en España representa un papel preponderante en nuestra economía, lo que además le sitúa en los primeros puestos de Europa y del mundo (Díez de Castro, Rodríguez y Navarro, 2007).

A raíz de estos datos, la importancia de la franquicia como sistema de distribución moderna ha sido ampliamente reconocida por académicos y profesionales, especialmente a partir de la década de los años 70 (Elango, 2007). Junto a ello, y a medida que la franquicia se fue imponiendo como un mecanismo de expansión empresarial su estudio fue cobrando cada vez más importancia. Sin embargo, a pesar del importante aumento en los últimos años del número de trabajos científicos (nacionales e internacionales) elaborados sobre el sistema de franquicia, todavía son insuficientes los estudios que se han centrado en este tema y la mayoría de los que lo han hecho, han tenido una doble orientación: en primer lugar, dar a conocer esta fórmula comercial, y en segundo lugar, explicar cómo debe llevarse a cabo su implantación empresarial. Por lo tanto, el espacio dedicado a la investigación científica es todavía inexistente o muy escaso (Diez y Rondán, 2004; Ramírez, Rondán y Guerrero, 2007). En este sentido, conocer el estado actual de la literatura sobre franquicia (las principales teorías y líneas de investigación aplicadas a este sistema de negocio), así como cuáles son los trabajos y autores de referencia, nos puede ayudar a enriquecer el estudio de la franquicia como uno de los principales mecanismos de expansión empresarial. Este es el objetivo de este trabajo: llevar a cabo una revisión de la literatura sobre franquicia, destacando las principales teorías aplicadas y líneas de investigación llevadas a cabo hasta el momento, así como las principales contribuciones realizadas por investigadores nacionales y extranjeros.

Para lograr estos objetivos, en el siguiente apartado realizaremos una revisión de literatura sobre las principales teorías aplicadas al estudiar el sistema de franquicia - teoría de la agencia, teoría de la escasez de recursos, teoría de la extensión del riesgo, teoría contractual, teoría de los costes de transacción y teoría de las señales-, explicando las principales contribuciones que realiza cada uno de los diferentes marcos teóricos en la investigación sobre franquicia. Seguidamente, describiremos las principales líneas de investigación en el sistema de franquicia, prestando especial atención a los trabajos elaborados por investigadores españoles bajo la forma de artículos de revistas, actas de congresos, monografías, capítulos de libro e incluso, tesis doctorales. Con ello, pretendemos ofrecer una visión amplia del estado de la literatura. Finalmente, concluiremos con un apartado destinado a resumir las ideas principales del trabajo, sus contribuciones (académicas y prácticas), así como las limitaciones y futuras líneas de investigación.

\section{LAS PRINCIPALES TEORÍAS EN EL SISTEMA DE FRANQUICIA}

Tal y como se ha expuesto en la sección anterior, el sistema de franquicia proporciona numerosas ventajas tanto al franquiciador como al franquiciado, por lo que se ha convertido en una fórmula muy popular que tiene un avance imparable tanto en los países más desarrollados comercialmente, como en los que tienen unas estructuras comerciales más 
anticuadas. Así pues, en EE.UU., -el país de mayor desarrollo de la franquicia-, al final de la década de los años 80 esta fórmula de negocio representaba cerca del 34\% del comercio minorista (Díez de Castro y Galán, 1989), mientras que en los últimos años se estima que supera el 40\% Welsh, Alon y Falbe, 2006).

Además, tal y como se recoge en el Anexo de este trabajo, la franquicia está presente en más de 50 sectores de actividad, en algunos de los cuales, como el de tintorería, mensajería, paquetería, moda o fast food, su presencia es abrumadora. Por lo tanto, los franquiciadores se están convirtiendo así en uno de los elementos más dinámicos en lo que respecta a generación de empresas y creación de empleo en todo el mundo. Por todo ello, la importancia académica y práctica de este sistema de negocio está siendo cada vez más reconocida, especialmente a partir de los últimos años, entre los investigadores (Elango, 2007).

Para tratar de comprender y analizar la complejidad del sistema de franquicia, así como las razones por las que una empresa adopta el sistema de franquicia para operar, son numerosas las teorías empleadas en los trabajos publicados hasta el momento (Combs y Ketchen, 2003). Cada una de ellas, está formada por un conjunto diferente de factores y es tratada de forma separada en la literatura (Carney y Gedaglovic, 1991). No obstante, son seis las teorías usadas de forma predominante en la literatura, tal y como se expone a continuación:

\subsection{Teoría de la agencia}

La teoría de la agencia (Jensen y Meckling, 1976; Fama y Jensen, 1983) es la más utilizada para explicar la relación entre el franquiciador y el franquiciado, así como el establecimiento y posterior desarrollo de los contratos que rigen tal relación (véase por ejemplo, Combs Ketchen, 1999; Alon, 2001; Sashi y Karuppur, 2002; Watson, Kirby y Egan, 2002; Quinn y Doherty, 2000; Garg y Rasheed, 2006: Ramírez, Rondán y Díez de Castro, 2007).

Este enfoque es particularmente útil al estudiar el sistema de franquicia ya que reconoce la existencia de dos partes (principal y agente), entre los que pueden existir algunas divergencias de intereses. En concreto, el principal (franquiciador) delega algunas tareas de trabajo en el agente (franquiciado) porque no tiene las capacidades, recursos o tiempo necesarios para llevarlas a cabo en primera persona. Sin embargo, esto no significa que el agente vaya a realizar su trabajo de la manera que más interese al principal, sino que por el contrario, es probable que trate de hacerlo siguiendo sus propios intereses (Garg y Rasheed, 2006). Asimismo, la teoría de la agencia asume que el agente puede verse tentado a ocultar información al principal acerca de sus verdaderas cualidades para desempeñar el trabajo que le han asignado (Jensen y Meckling, 1976). Esta situación obliga al principal a realizar una importante asignación de recursos en las tareas de vigilancia y control de las actividades llevadas a cabo por el agente, una vez que éste haya sido contratado (Shane, 1996).

Sin embargo, y a pesar de los costes antes expuestos, la teoría de la agencia defiende la franquicia como forma de expansión empresarial, ya que a través de este sistema el franquiciado tiene más incentivos a maximizar sus esfuerzos, sobre todo si se compara con otro tipo de formas de expansión empresarial. Esto se debe a que en la franquicia, el franquiciado puede tener menos incentivos a actuar de manera oportunista frente a los intereses del franquiciador ya que éste es el propietario del establecimiento -en el cual ha realizado importantes inversiones de capital y tiempo-, por lo que también estará interesado en que 
el negocio funcione bien (Brickley y Dark, 1987). En cambio, en la relación empleadorgerente es más difícil que los intereses de ambos están alineados (Combs y Ketchen, 1999).

\subsection{Teoría de la escasez de recursos}

Otra teoría en la que se han apoyado diferentes trabajos para estudiar el sistema de franquicia es la teoría de los recursos escasos (Combs y Ketchen, 1999; Alon, 2001; Watson, Kirby y Egan, 2002; Sigué y Rebolledo, 2004; Ramírez, Rondán y Díez de Castro, 2007, entre otros). A través de este enfoque se sostiene que los sistemas de franquicia tienen un ciclo de vida que permite hacer previsiones sobre sus procesos y algunos elementos de su estructura (Oxenfeldt y Kelly, 1969).

El punto de partida de la teoría de la falta de recursos es que la franquicia no es la mejor forma de desarrollo empresarial. Por ello, para lograr mejores utilidades, buen control y evitar complicaciones legales, las empresas deben crecer mediante puntos de venta propios. Así pues, la expansión a través de franquicias únicamente es preferible para puntos de ventas marginales. Asimismo, y siempre según este enfoque, el sistema de franquicia es un paliativo temporal que ayuda a solucionar la falta de recursos en las primeras etapas de desarrollo del negocio, así como cuando la empresa se enfrenta a problemas de disponibilidad de recursos (Hunt, 1973; Caves y Murphy, 1976; Carney y Gedajlovic, 1991).

Así pues, la teoría de escasez de recursos sostiene que los franquiciadores adoptan la franquicia como medio de desarrollo empresarial, principalmente porque no tienen suficientes recursos propios y quieren aprovechar la aportación de los franquiciados en este sentido (Sigué y Rebolledo, 2004). Dicha contribución se centra en tres tipos de recursos: financieros, capital humano, y por último, el conocimiento del mercado local (Lafontaine y Kaufmann, 1994: Ketchen, Combs y Upson, 2006). El incremento de recursos intelectuales es importante para los franquiciadores ya que ello hace que la cadena vaya creciendo con unidades de negocio bien gestionadas. Por otro lado, los franquiciadores necesitan capital financiero para crecer, el cual puede ser proporcionado por los franquiciados a un coste muy bajo (Ramírez, Rondán y Díez de Castro, 2007).

Tal y como se ha apuntado anteriormente, la teoría de escasez de recursos ha tenido una gran influencia sobre la investigación del sistema de franquicia. Sin embargo, en una revisión de la literatura llevada a cabo por Dant, Paswan y Kaufmann (1996) sobre los estudios empíricos realizados al analizar la franquicia como mecanismo de expansión empresarial, los resultados concluyeron que los hechos no siempre sostienen esta teoría. No obstante, ocho años más tarde Sigué y Rebolledo (2004) llevaron a cabo cuatro estudios de caso y los resultados obtenidos concluyeron que en tres de ellos, la teoría de la escasez de recursos sí que se veía sostenida.

\subsection{Otros enfoques teóricos: teoría de la extensión del riesgo, teoría contractual, teoría de los costes de transacción y teoría de las señales}

Según Combs y Castrogiovanni (1994), junto a la teoría de la agencia y la teoría de la escasez de recursos, la teoría de la extensión del riesgo ha sido predominantemente 
empleada para explicar la estrategia del franquiciador, al afirmar que los franquiciadores hacen propias las unidades más interesantes y ofrecen como franquiciadas las que suponen un riesgo mayor. Estas tres teorías individualmente no han logrado una total explicación de las razones que llevan a los empresarios a usar la franquicia como mecanismo de expansión empresarial, pero sí han contribuido cada una de ellas de forma parcial. Por ello, más que posicionarse en una teoría en detrimento de las otras, algunos autores sostienen la necesidad de establecer un enfoque integrador de todas ellas (Rondán, Navarro y Díez de Castro, 2007).

La teoría contractual, por su parte, establece que cuanto mayor sea el número de establecimientos, más integrada estará la cadena para evitar riesgos de retención sobre los activos específicos y estimular la inversión en los mismos (Rodríguez y Navarro, 2007). Así pues, según este enfoque, el franquiciador decidirá franquiciar una unidad si el coste de supervisión es menor que si dirige el establecimiento una persona de la empresa (Shane, 1996). Esto puede provocar que el coste de una unidad propia sea mayor que el de una ajena, lo que las convierte en menos rentables (Holmberg y Morgan, 2003).

Ahora bien, al hablar de las teorías más utilizadas para explicar el sistema de franquicia, no se puede omitir la teoría de los costes de transacción, la cual, junto con la teoría de la agencia, domina la literatura de franquicias (Burton, Cross y Rhodes, 2000). La teoría de los costes de transacción es una aplicación de la concepción de la empresa defendida por Coase (1937) y Williamson (1975), a través de la cual las empresas son vistas como agentes eficientes (Chang y Rosenzweig, 2001) que subcontratan aquellas actividades que los agentes externos proporcionan a un coste menor del que habría soportado la empresa si hubiese realizado internamente dicha actividad (Erramilli y Rao, 1993). Sin embargo, cuando la empresa acude al mercado para subcontratar las actividades que ella realiza de forma más cara y menos eficiente, se enfrenta al riesgo de que sus socios actúen de manera oportunista y quieran aprovecharse de la racionalidad limitada de los agentes que operan en el mercado. Esto conlleva que la compañía se vea obligada a soportar determinados costes relativos a la negociación del contrato, así como a la vigilancia y control del cumplimiento de los términos acordados en el mismo (Zou, Taylor y Cavusgil, 2005).

Tal y como se ha indicado anteriormente, esta perspectiva ha sido utilizada varias veces por los investigadores interesados en analizar el sistema de franquicia (Watson, Kirby y Egan, 2002). En especial, las razones para su internacionalización (Sashi y Karuppur, 2002; Michael, 2003; Elango, 2007), así como la selección de la forma de entrada en nuevos mercados (Burton, Cross y Rhodes, 2000). Esto se debe a que en el estudio del sistema de franquicia no sólo hay que tener en cuenta las relaciones principal-agente sino además, los costes de transacción que se derivan del acuerdo contractual entre el franquiciador y franquiciado, sobre todo cuando el contrato se firma entre agentes separados cultural y geográficamente.

Por último, es preciso señalar que numerosos trabajos han optado por analizar el sistema de franquicia desde otra perspectiva teórica: la teoría de las señales (Gallini y Lutzt, 1992). Este enfoque defiende que los sectores que se basan en bienes intangibles deben emitir señales a través de aspectos observables para que el público pueda valorarlos. Estas señales son enviadas a los clientes, competidores, proveedores o a cualquier agente que pueda estar implicado en la empresa y con ello, facilitar la toma de decisiones de los potenciales compradores (Michael, 2009). 
En el contexto del sistema de franquicia, la teoría de las señales ha sido objeto de análisis en numerosos trabajos (Gallini y Lutzt, 1992; Lafontaine, 1993; Windsperger, 2001; Michael, 2009, entre otros) para explicar diferentes decisiones adoptadas por los franquiciadores, tales como la expansión del negocio a través de tiendas propias frente a tiendas franquiciadas. En este sentido, la teoría de las señales sugiere que el franquiciador posee información privilegiada sobre la verdadera rentabilidad y viabilidad del negocio. Es por esto que algunos franquiciados prefieren iniciar su expansión a través de tiendas propias en contraposición a las tiendas franquiciadas y con ello, emitir al mercado una señal de negocio solvente y rentable puesto que el propio franquiciador no teme invertir en él. Según la teoría de las señales, ello incrementaría el número de agentes interesados en convertirse en futuros franquiciados de la empresa. No obstante, este argumento no siempre ha encontrado apoyo empírico (Lafontaine, 1993; Dant, Perrigot y Cliquet, 2008, entre otros).

Asimismo, la teoría de las señales ha sido empleada para señalar que los franquiciadores que reclaman mayores royalties a sus franquiciados muestran una menor probabilidad de fracaso en su negocio (Gallini y Lutz, 1992; (Shane 1998). Esto se debe a que los agentes consideran que sólo los negocios de mayor calidad y experiencia están en disposición de reclamar elevados royalties. Por ello, al creer que el franquiciador ofrece un negocio de calidad y sobrada experiencia, aumentaría el número de agentes interesados en convertirse en franquiciado -a pesar de la elevada cuantía del royalty-, lo que reduciría la probabilidad de fracaso del negocio. Sin embargo, algunos trabajos han rechazado esta relación (Lafontaine y Shaw 1999) o muestran una relación negativa entre la cuantía del royalty y la edad de la cadena (Lafontaine, 1992; Shane, Shankar y Aravidakshan, 2006), lo que permite seguir atrayendo a nuevos fraquiciados y reducir la probabilidad de fracaso. Del mismo modo, al analizar la relación entre la cuantía del royalty y el canon de entrada con la supervivencia de la empresa, los resultados obtenidos en Bordonaba, Palacios y Redondo (2009) rechazaron que las cadenas que imponen un mayor royalty o canon de entrada muestren una menor probabilidad de fracaso.

En definitiva, el desarrollo de la franquicia se sustenta sobre estas seis teorías. Atendiendo a dichas teorías, la literatura ha estudiado el sistema de franquicia desde diferentes perspectivas, tal y como se expone a continuación.

\section{PRINCIPALES LÍNEAS DE INVESTIGACIÓN EN EL SISTEMA DE FRANQUICIA}

El sistema de franquicia comenzó a despertar el interés de los investigadores a partir de la década de los años 60, época en la que su uso se generalizó en los EE.UU. (Alon y McKee, 1999). Durante las décadas siguientes, la franquicia experimentó un crecimiento exponencial y alcanzó un notable éxito durante los años noventa (Ryans, Lotz y Krampf, 1999), de manera que más de un tercio de las ventas minoristas se hicieron a través de franquicias (Garg, 2005). A comienzos de siglo XXI, este sistema era utilizado en cerca de 320.000 negocios de EE.UU. y en más de 75 industrias diferentes, dando empleo a más de 8 millones de personas (Dant y Kaufmann, 2003). En la actualidad, la red de franquicias supone en Estados Unidos una cifra de ventas anual de más de 800 billones de dólares, con más de 2.300 franquiadores y 550.000 puntos de venta franquiciados (Elango, 2007). 
Fruto de este crecimiento, el número de trabajos publicados sobre el sistema de franquicia ha aumentado considerablemente en los últimos años, sobre todo en la literatura norteamericana y británica donde la implantación de esta fórmula de distribución moderna es mayor sobre todo si se compara con países de Latinoamérica, África, Asia y Oceanía (Jones, 2003). Por otra parte, a medida que la franquicia se fue imponiendo como sistema de crecimiento empresarial y forma de entrada a nuevos mercados, el estudio de la internacionalización de la franquicia fue cobrando importancia entre los académicos y profesionales del marketing. No obstante, todavía son relativamente escasos los trabajos teóricos y sobre todo empíricos que se han centrado en tema, en buena parte debido a la dificultad de conseguir datos sobre este tipo de empresas (véase por ejemplo, Eroglu, 1992; Alon y McKee, 1999; Quinn y Doherty, 2000; Sahshi y Karuppur, 2002; Jones, 2003; Garg y Rasheed, 2006; Welsh, Alon y Falbe, 2006).

En resumen, el sistema de franquicia es un tema que despierta un creciente interés entre los investigadores, debido a su importancia cada vez mayor como mecanismo de crecimiento empresarial. Además, en los últimos años se ha consolidado como un sistema de expansión internacional por lo que su importancia académica y práctica está siendo cada vez más reconocida (Elango, 2007). Esto conlleva que se trate de una disciplina académica relativamente joven, sobre todo si se compara con otras áreas, por lo que el volumen de trabajos elaborados al respecto es todavía insuficiente para comprender la complejidad del sistema de franquicia. Por ello, son muchos y recientes los estudios académicos que animan a los investigadores a profundizar en el estudio de esta forma de negocio, especialmente por lo que respecta a la estrategia de internacionalización y selección de mercados llevada a cabo por las cadenas franquiciadoras, donde el número de trabajos publicados al respecto es reducido (Alon y McKee, 1999; Sashi y Karuppur, 2002; Michael, 2003, Garg y Rasheed, 2006; Welsh, Alon y Falbe, 2006).

Atendiendo a las diferentes líneas de investigación en las que puede clasificarse los estudios realizados hasta el momento sobre el sistema de franquicia, es preciso indicar que el primer trabajo llevado a cabo para su identificación fue realizado por Elango y Fried (1997). Basándonos tanto en dicho trabajo, como en otros estudios más recientes (Díez de Castro, Rodríguez y Navarro, 2007; Elango, 2007) podemos dividir en cuatro grandes grupos las líneas de investigación llevadas a cabo al analizar la franquicia. El primero de ellos se refiere a las razones sociales de la franquicia, donde se encuadran los trabajos referidos al balance social de la franquicia, el contrato de franquicia y la ética de la franquicia.

El segundo grupo, se centra en la expansión de la franquicia y como tal, analiza las razones que el franquiciador tiene para franquiciar su negocio o abandonar el sistema de franquicia, la expansión a través de unidades propias versus franquiciadas, el proceso de internacionalización de la franquicia y por último, la selección de franquiciados y franquiciadores.

La tercera línea de investigación sobre el sistema de franquicia está orientada al análisis de las características del franquiciado y franquiciadores. Por último, el cuarto y último gran grupo en el que es posible dividir la literatura sobre el sistema de franquicia, se refiere a la relación entre la figura del franquiciador y sus franquiciados. La Tabla 1 resume esta clasificación e incluye algunas de las referencias más citadas por los investigadores españoles en sus trabajos. 
Tabla 1

Principales líneas de investigación en el sistema de franquicia

\begin{tabular}{|c|c|}
\hline $\begin{array}{l}\text { LINEAS DE } \\
\text { INVESTIGACION }\end{array}$ & REFERENCIAS MÁS DESTACADAS \\
\hline \multirow{3}{*}{$\begin{array}{l}\text { 1) Razones } \\
\text { sociales de la } \\
\text { franquicia }\end{array}$} & i) Balance social de la franquicia (Hunt, 1972) \\
\hline & $\begin{array}{l}\text { ii) El contrato de franquicia (Caves y Murphy, 1976; Mathewson y Winter, } \\
\text { 1985; Hadfield, 1990; Lafontaine y Kaufmann, 1994; Lafontaine y Shaw, 1996) }\end{array}$ \\
\hline & iii) Ética de la franquicia (Preble y Hoffman, 1999; Fernández y Martín, 2006) \\
\hline \multirow{4}{*}{$\begin{array}{l}\text { 2) Expansión de } \\
\text { la franquicia }\end{array}$} & $\begin{array}{l}\text { i) Razones para franquiciar o para abandonar el sistema de franquicia } \\
\text { (Oxenfeldt y Kelly, 1968; Bacus, Bacus y Human, 1993; Julian y Castrogio- } \\
\text { vanni, 1995; Combs y Ketchen, 1999; Alon, 2001; Nair, 2001; Castrogio- } \\
\text { vanni y Justis, 2002; López y Ventura, 2002; Watson, Kirby y Egan, 2002; } \\
\text { Sigué y Rebolledo, 2004; Garg, 2005) }\end{array}$ \\
\hline & $\begin{array}{l}\text { ii) Unidades propias versus franquiciadas (Bradach y Eckles, 1989; Tho- } \\
\text { mas, O’Hara y Musgrave, 1990; Dant, Kaufmann y Paswan, 1992; Thomp- } \\
\text { son, 1992; Calderón, 2002; Garg. y Rasheed, 2006. }\end{array}$ \\
\hline & $\begin{array}{l}\text { iii) Internacionalización de la franquicia (Hackett, 1976; Eroglu, 1992; Hus- } \\
\text { zagh, Huszagh y McIntyre, 1992; Cahn y Justis, 1993; Kedia y otros, 1994; } \\
\text { Zietlow, 1995; Alon y McKee, 1999; Combs y Ketchen, 1999; Alon y Banai, } \\
\text { 2000; Quinn y Doherty, 2000; Hoffman y Preble, 2001; Sashi y Karuppur, } \\
\text { 2002; Jones, 2003; Michael, 2003; Hoffman y Preble, 2004; Elango, 2007) }\end{array}$ \\
\hline & $\begin{array}{l}\text { iv) Selección de franquiciados y franquiciadores (Tatham, Douglas y Bush, } \\
\text { 1972; Knight, 1986; Morrison, 1997; Fenwich y Strombon, 1998; Michael, } \\
\text { 2003; Ramírez, Guerrero y Rondán, 2006; Ramírez, Rondán y Guerrero, 2007) }\end{array}$ \\
\hline $\begin{array}{l}\text { 3) Característi- } \\
\text { cas del franqui- } \\
\text { ciado y franqui- } \\
\text { ciador }\end{array}$ & $\begin{array}{l}\text { (Tatham, Douglas y Bush, 1972; Edens, Self y Grider, 1976; Knight, 1986; } \\
\text { Petersen y Dant, 1990; Withane, 1991; DeCeglie, 1993; Castrogiovanni, } \\
\text { Justis y Julian (1993); Castrogiovanni, Bennet y Combs, 1995; Hing, 1995; } \\
\text { Kaufmann y Stanworth, 1995; Falbe y Trombon, 1998; Berni, 2002; Kassel- } \\
\text { mann, de Beer y Vermeulen, 2002) }\end{array}$ \\
\hline $\begin{array}{l}\text { 4) Relaciones } \\
\text { franquiciador- } \\
\text { franquiciado }\end{array}$ & $\begin{array}{l}\text { (Hunt y Nevin, 1974; Lusch, 1977; Zeller, Achabal y Brown, 1980; Sen, } \\
\text { 1993; Lafontaine y Slade, 1997; Morrison, 1997; Sanders, 2002; García, } \\
\text { Sanzo y Trespalacios, 2004) }\end{array}$ \\
\hline
\end{tabular}

Fuente: Elaboración propia

En relación a los investigadores españoles, la mayor parte de los trabajos sobre el sistema de franquicia han sido elaborados a partir de la década de los años 80, etapa a partir de la cual el sistema de franquicia español experimentó una importante evolución e inició su despegue en nuestro país (Rondán, Navarro y Díez de Castro, 2007). Como consecuencia, el sistema de franquicia desempeña actualmente un papel preponderante en España lo que nos sitúa en los primeros puestos de Europa y del mundo en términos de facturación anual y empleos generados (Tormo \& Asociados, 2008). Junto a ello, el sistema de franquicia español ocupa la quinta posición mundial en términos de número de enseñas y establecimientos franquiciados, tal y como se recoge en las Figuras 1 y 2. 


\section{Gráfico 1}

Los países con mayor número de cadenas franquiciadoras asentadas en su territorio

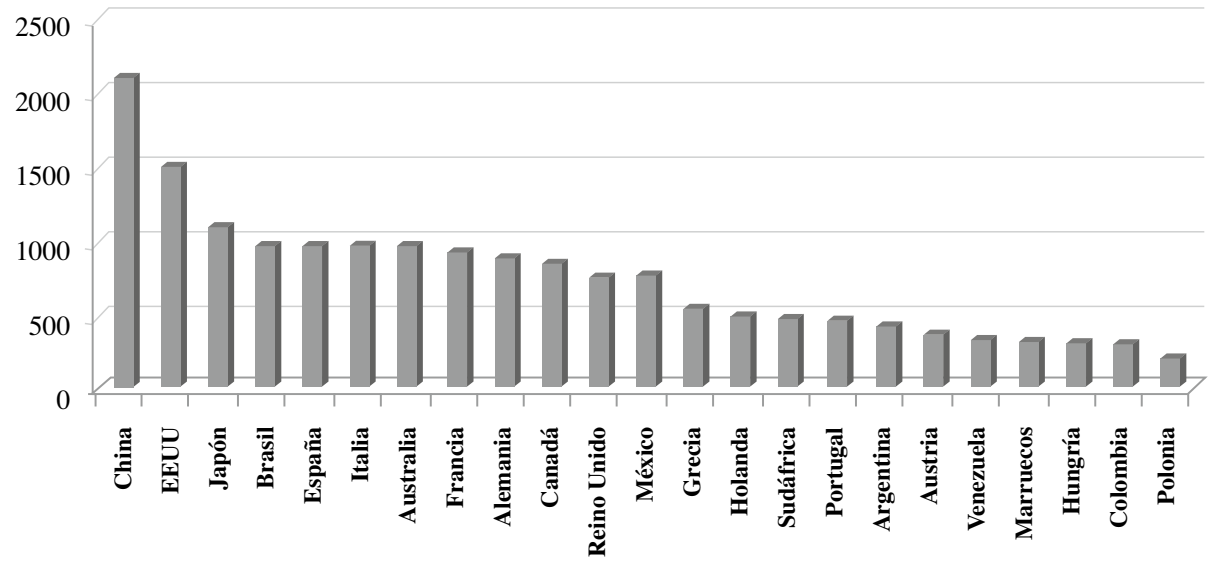

Fuente: Elaboración propia a partir de los datos publicados en 2008 por la International Franchise Association

Gráfico 2

Los países con mayor número de establecimientos franquiciados asentados en su territorio

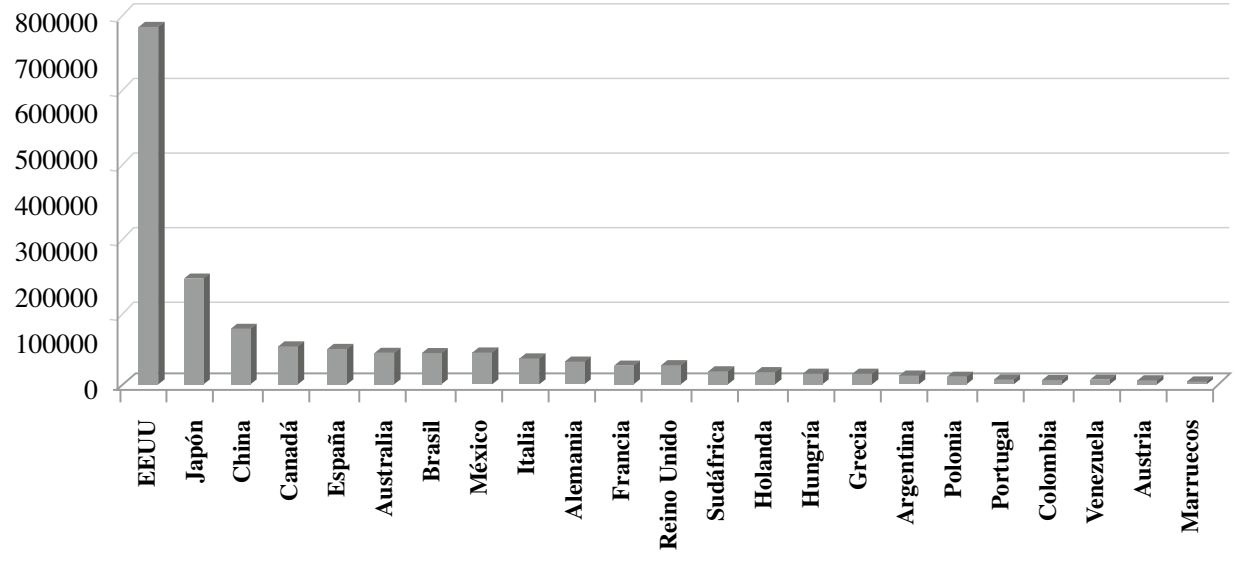

Fuente: Elaboración propia a partir de los datos publicados en 2008 por la International Franchise Association

Por ello, no es de extrañar el elevado número de trabajos que los investigadores españoles están publicando sobre la franquicia durante las dos últimas décadas, especialmente, en los últimos años. Asimismo, son numerosos los trabajos sobre el sistema de franquicia elaborados por autores españoles que han sido publicados en las actas de congresos, tanto nacionales como internacionales. Por último, es preciso destacar el importante número de investigadores españoles que han elaborado monografías o colaborado en la redacción de diversos libros relativos al sistema de franquicia.

Atendiendo a las líneas de investigación abordadas por nuestros autores, la Tabla 2 recoge los temas tratados y además, los clasifica en función del medio de difusión del trabajo: revista 
científica, ponencia publicada, monografía o capítulo de libro. A través de este análisis podemos afirmar que, si bien es cierto que los investigadores españoles han abordado en sus publicaciones en revistas científicas y ponencias casi todas las líneas y sub-líneas de investigación identificadas en la Tabla 1, la temática se reduce con respecto a las monografías y capítulos de libro. De este modo, con respecto a este último grupo, la línea de investigación prioritaria es el contrato de franquicia (Gallego y Fernández, 1991; Ruiz, 1991; Díaz-Bernardo, Iniesta y Nueno, 1998; Díez de Castro y Galán, 1998; Bermúdez, 2002; Alonso, 2003; Barreiros y otros, 2004; Díez de Castro, Navarro y Rondán, 2006b; Rondán, Navarro y Díez de Castro, 2007), seguida de las características del franquiciado y franquiciador (Bolea de Anta, 1990; Ramírez, Rondán y Diez de Castro, 2007), las razones para expandirse a través de la franquicia (Solís y González, 2007) y su proceso de internacionalización (Cerviño, 1999).

En conjunto, podemos afirmar que el contrato de franquicia y el análisis de las características de los franquiciados y/o franquiciadores son algunas de las líneas de investigación preferidas por los investigadores españoles interesados en estudiar el sistema de franquicia. Por el contrario, tan sólo hemos encontrado un trabajo que analizase el balance social de la franquicia como tema principal (Rondán, Díez de Castro y Navarro, 2006b) y éste, fue divulgado bajo la forma de ponencia. Otra línea que tampoco ha recibido mucha atención por nuestros investigadores es la decisión de expansión a través de unidades propias versus franquiciadas. En este sentido, no hemos encontrado ninguna ponencia que analizase el tema y son escasos los trabajos publicados en revistas (Martínez, 1994c) o capítulos de libro (Díez de Castro, Rodríguez y Navarro, 2007), al respecto.

Tabla 2

Difusión científica llevada a cabo por autores españoles sobre el sistema de franquicia

\begin{tabular}{|c|c|}
\hline $\begin{array}{l}\text { MEDIO DE } \\
\text { DIFUSIÓN }\end{array}$ & LÍNEA DE INVESTIGACIÓN \\
\hline \multirow{8}{*}{$\begin{array}{l}\text { Artículos } \\
\text { publicados } \\
\text { en revistas } \\
\text { científicas }\end{array}$} & $\begin{array}{l}\text { El contrato de franquicia (Díez de Castro y Galán 1989; Martínez; 1994a; } \\
\text { 1994b; 1994c; 1994e; Bermejo, 2002; Díez de Castro y Rondán, 2004; Ribei- } \\
\text { ro, 2005; Bordonaba, Lucía y Polo, 2008a; Bordonaba, Lucía y Polo, 2009) }\end{array}$ \\
\hline & Ética de la franquicia (Ribeiro y Ribes, 2000; Fernández y Martín, 2006) \\
\hline & $\begin{array}{l}\text { Razones para franquiciar o para abandonar el sistema de franquicia } \\
\text { (Calderón, 2002; López y Ventura, 2002; Tormo, 2002; Sigué y Rebolledo, } \\
\text { 2004; Bordonaba, Lucía y Polo, 2008c) }\end{array}$ \\
\hline & Unidades propias versus franquiciadas (Martínez, 1994c) \\
\hline & $\begin{array}{l}\text { Internacionalización de la franquicia (López y González, 2001b; Múgica y } \\
\text { Yagüe, 2004; Sánchez y Pla, 2004; Baena, 2009; Baena y Cerviño, 2009) }\end{array}$ \\
\hline & $\begin{array}{l}\text { Selección de franquiciados y/o franquiciadores (Ramírez, Guerrero y Ron- } \\
\text { dán, 2006; Ramírez, Rondán y Guerrero, 2007) }\end{array}$ \\
\hline & $\begin{array}{l}\text { Características del franquiciado y franquiciador (López y Ventura, 2001; } \\
\text { Bordonaba, Lucía y Polo, 2008b; Solís y González, 2008) }\end{array}$ \\
\hline & $\begin{array}{l}\text { Relación franquiciador-franquiciado (García, Sanzo y Trespalacios, 2004; } \\
\text { Fernández y Melián, 2005; Benavides, Minguela y López, 2008) }\end{array}$ \\
\hline
\end{tabular}




\begin{tabular}{|c|c|}
\hline $\begin{array}{l}\text { MEDIO DE } \\
\text { DIFUSIÓN }\end{array}$ & LÍNEA DE INVESTIGACIÓN \\
\hline \multirow{8}{*}{$\begin{array}{l}\text { Ponencias } \\
\text { publicadas } \\
\text { en Actas de } \\
\text { Congresos }\end{array}$} & Balance social de la franquicia (Rondán, Díez de Castro y Navarro, 2006b) \\
\hline & El contrato de franquicia (Palacios, Polo y Bordonaba, 2005) \\
\hline & $\begin{array}{l}\text { Ética de la franquicia (Díez de Castro, Navarro y Rondán, 2006a; Gámez y } \\
\text { otros, 2008) }\end{array}$ \\
\hline & $\begin{array}{l}\text { Razones para franquiciar o para abandonar el sistema de franquicia (Cal- } \\
\text { derón, 2000; Maríz, García y Calvo, 2004; Bordonaba, Lucía y Polo, 2008c; } \\
\text { Rondán y otros, 2008) }\end{array}$ \\
\hline & $\begin{array}{l}\text { Internacionalización de la franquicia (López y González, 2001a; Baena y } \\
\text { Cerviño, 2008a; 2008b; 2008c) }\end{array}$ \\
\hline & Selección de franquiciados y/o franquiciadores (Padilla, 2002) \\
\hline & $\begin{array}{l}\text { Características del franquiciado y franquiciador (Aquino y Rondán, 1999; } \\
\text { Navarro, Díez de Castro y Rondán, 2005; Navarro, Rondán y Diez de Cas- } \\
\text { tro, 2005; Ramírez, 2005; Navarro y Díez de Castro, 2006; Ramírez y otros, } \\
\text { 2006; Rondán, Díez de Castro y Navarro, 2006a; Rondán, Navarro y Díez } \\
\text { de Castro, 2006) }\end{array}$ \\
\hline & $\begin{array}{l}\text { Relación franquiciador-franquiciado (Bordonaba y Polo, 2003; Martín, } \\
\text { Fernández y Beerli, 2005) }\end{array}$ \\
\hline \multirow{5}{*}{$\begin{array}{l}\text { Monografías } \\
\text { y Capítulos de } \\
\text { Libro }\end{array}$} & $\begin{array}{l}\text { El contrato de franquicia (Gallego y Fernández, 1991; Ruiz, 1991; Díaz- } \\
\text { Bernardo, Iniesta y Nueno, 1998; Díez de Castro y Galán, 1998; Bermúdez, } \\
\text { 2002; Alonso, 2003; Barreiros y otros, 2004; Díez de Castro, Navarro y } \\
\text { Rondán, 2006b; Rondán, Navarro y Díez de Castro, 2007) }\end{array}$ \\
\hline & $\begin{array}{l}\text { Razones para franquiciar o abandonar el sistema de franquicia (Solís y } \\
\text { González, 2007) }\end{array}$ \\
\hline & $\begin{array}{l}\text { Unidades propias versus franquiciadas (Díez de Castro, Rodríguez y Nava- } \\
\text { rro, 2007) }\end{array}$ \\
\hline & $\begin{array}{l}\text { Características del franquiciado y franquiciador (Bolea de Anta, 1990; } \\
\text { Ramírez, Rondán y Diez de Castro, 2007) }\end{array}$ \\
\hline & Internacionalización de la franquicia (Cerviño, 1999) \\
\hline
\end{tabular}

Fuente: Elaboración propia

Junto a lo anteriormente expuesto, el estudio que nuestros investigadores han realizado sobre el sistema de franquicia no sólo ha derivado en un importante número trabajos publicados tanto en revistas científicas, ponencias en congresos, monografías o capítulos de libro, sino que además, ha sido objeto de análisis en veintinueve tesis doctorales. En la mayoría de los casos, estos trabajos han analizado el sistema de franquicia desde un punto de vista económico (Rigol, 1989; Guzmán, 1995; Arribas, 1996; Vázquez, 1998; Calderón, 1999; López, 1999; Moro, 1999; Perales, 1999; Sancho, 2000; Bermúdez, 2001; Rodrígues, 2002; Bordonaba, 2003; Fernández, 2003; Curz, 2006; Jiménez, 2006; Mariz, 2007; Ramírez, 2007; Rodríguez, 2007; Baena, 2008; Lucía, 2008; Gámez, 2009; Solís, 2009). Sin embargo, es preciso señalar la existencia de una tesis doctoral perteneciente al área de comunicación audiovisual y tecnologías de la información (Monsterrat, 2005), así como 
seis tesis doctorales vinculadas al ámbito jurídico (Giner, 1993; Mauricio, 1994; Echebarría, 1995; Mayorga, 2002; Sánchez, 2005; Martí, 2009).

\section{DISCUSIÓN, LIMITACIONES Y FUTURAS LINEAS DE INVESTIGACIÓN}

A lo largo del siglo XX, el sistema de franquicia ha vivido un escenario de creación y desarrollo realmente espectacular. Este sistema proporciona numerosas ventajas tanto al franquiciador como al franquiciado, por lo que se ha convertido en una fórmula muy popular que tiene un avance imparable en los países más desarrollados comercialmente. Además, la franquicia está presente en casi todos los sectores de actividad, en algunos de los cuales como el de tintorería, mensajería, paquetería, moda o fast food, su presencia es abrumadora. Por lo tanto, los franquiciadores se están convirtiendo así en uno de los elementos más dinámicos por lo que respecta a la generación de empresas y creación de empleo en todo el mundo. Como consecuencia, la importancia académica y práctica de este sistema de negocio está siendo cada vez más reconocida, especialmente a partir de los últimos años (Elango, 2007).

Este trabajo pretende proporcionar al lector una completa revisión del estado actual del sistema de franquicia, tanto en España como en el resto del mundo, por lo que creemos que en muchos aspectos podría ayudar a otros investigadores interesados en analizar el sistema de franquicia como mecanismo de expansión empresarial. Además, se trata de uno de los pocos estudios que repasa el estudio del sistema de franquicia, prestando especial interés a las principales teorías y líneas de investigación seguidas por la literatura. En concreto, y siguiendo la línea iniciada por Elango y Fried (1997) y Díez de Castro y Rondán (2004), este estudio identifica las principales teorías aplicadas al estudiar el sistema de franquicia - teoría de la agencia, teoría de la escasez de recursos, teoría de la extensión del riesgo, teoría contractual, teoría de los costes de transacción y teoría de las señales-, y explica las contribuciones que realiza cada una de ellas en la investigación sobre franquicia.

Por otra parte, la revisión llevada a cabo en este trabajo señala las cuatro grandes líneas de investigación que predominan sobre el resto. La primera de ellas se refiere a las razones sociales de la franquicia, donde se encuadran los trabajos referidos i) al balance social de la franquicia, ii) el contrato de franquicia, así como iii) la ética de la franquicia. El segundo grupo se centra en la expansión de la franquicia y como tal, analiza i) las razones que el franquiciador tiene para franquiciar su negocio o para abandonar el sistema de franquicia, ii) las unidades propias versus las franquiciadas, iii) las internacionalización la franquicia y por último, iv) la selección de franquiciados y/o franquiciadores. La tercera línea de investigación está orientada al análisis de las características del franquiciado y franquiciador. Finalmente, el cuarto y último gran grupo en el que es posible dividir la literatura sobre el sistema de franquicia, se refiere a la relación entre el franquiciador y sus franquiciados.

Esta clasificación nos ha servido para compararla con las líneas de investigación seguidas por los autores españoles interesados en estudiar el sistema de franquicia. En este sentido, no se aprecian diferencias significativas ya que, en conjunto, nuestros autores han abordado todas las líneas y sub-líneas de investigación anteriormente mencionadas. Sin embargo, su distribución no es equitativa y varía en función del medio de difusión del que se trate: revista científica, ponencia, monografías o capítulos de libro. Así pues, podemos 
destacar que el análisis de la selección de franquiciados y/o franquiciadores sólo ha sido llevado a cabo en dos trabajos publicados en revistas científicas (Ramírez, Guerrero y Rondán, 2006; Ramírez, Rondán y Guerrero, 2007) y una ponencia (Padilla, 2002).

Del mismo modo, tal y como se ha expuesto en la sección anterior, otros temas que han recibido escasa atención por nuestros autores es el balance social de la franquicia y la expansión de la franquicia a través de unidades propias versus franquiciadas. Por el contrario, temas como el contrato de franquicia y las características del franquiciado o franquiciador han sido ampliamente analizados por los investigadores españoles. Asimismo, es preciso señalar el reciente interés de dos sub-líneas que aunque no habían sido muy tratados por nuestros investigadores, ahora están recibiendo notable atención, puesto que todos los trabajos sobre estos temas han sido publicados a partir de 1999. Se trata, en primer lugar, de la ética de la franquicia (Ribeiro y Ribes, 2000; Díez de Castro, Navarro y Rondán, 2006a; Fernández y Martín, 2006; Gámez y otros, 2008) y en segundo lugar, de la internacionalización de la franquicia (Cerviño, 1999; López y González, 2001a; López y González, 2001b; Múgica y Yagüe, 2004; Sánchez y Pla, 2004; Baena y Cerviño, 2008a; 2008b; 2008c; Baena, 2009; Baena y Cerviño, 2009).

En el ámbito académico no existen muchos artículos que analicen el sistema de franquicia y que además, identifiquen la literatura, así como las principales teorías y líneas de investigación desarrolladas sobre esta fórmula de negocio. Este aspecto nos parece importante y por ello, se han manejado ciento setenta artículos para clasificar los trabajos existentes e identificar las líneas de investigación, las teorías más empleadas y los principales autores en el área. Dado que en los últimos años se está produciendo un avance muy importante en España en la investigación sobre el sistema de franquicia, hemos prestado especial atención a los trabajos elaborados por autores españoles: artículos publicados en revistas científicas, ponencias presentadas en congresos, monografías y capítulos de libro. Con ello, pretendemos ofrecer una visión actualizada del estado de la literatura que nos permita identificar las líneas de trabajo abiertas hasta la fecha, así como futuras líneas de investigación.

Sin embargo, como en cualquier estudio científico, el investigador junto a las fortalezas de su trabajo, debe conocer sus debilidades. En este sentido, la principal limitación de este artículo emana de lo difícil que resulta llevar a cabo una revisión exhaustiva de los trabajos realizados hasta la fecha sobre el sistema de franquicia. Esto se debe a que buena parte de las bases de datos existentes sólo recogen publicaciones de habla inglesa, excluyendo por tanto las investigaciones realizadas en la lengua de países donde el sistema de franquicia registra una de las tasas de crecimiento más importantes, como Francia y sobre todo, España. No obstante, a raíz de la revisión de literatura llevada a cabo en este trabajo, hemos podido constatar la tendencia creciente de trabajos publicados en Inglés por los investigadores españoles.

Con respecto a las futuras líneas de investigación, este estudio nos ha permitido detectar diferentes áreas del sistema de franquicia poco exploradas hasta el momento. Así pues, sería interesante analizar el sistema de franquicia bajo la figura de otros agentes diferentes del franquiciado o el franquiciador, como por ejemplo, el máster franquiciador. Junto a ello, proponemos el estudio de los perfiles del franquiciado y del franquiciador en diferentes países. Ello nos permitiría contrastar la existencia de diferencias significativas entre ellos. 
Por otra parte, creemos que sería conveniente trabajar en la elaboración de un modelo que permita resolver uno de los principales problemas de las franquicias de servicios: la determinación de la cuantía del royalty. En este sentido, varios trabajos afirman que las cadenas cuya línea de negocio gira en torno a un bien intangible (servicio) encuentran más difícil controlar el desempeño elaborado por el franquiciado, así como los resultados que éste ha obtenido en la gestión del negocio (Shane, 1998; Erramilli, Agarwal y Dev, 2002). Por el contrario, en las cadenas cuya línea de actividad se orienta al producto, los sistemas están mecanizados y los procesos estandarizados por lo que es más fácil controlar al franquiciado (Burton, Cross y Rhodes, 2000). De este modo, dado que la cuantía del royalty suele fijarse como un porcentaje de las ventas brutas obtenidas por el franquiciado, cuanto más efectivo sea el control de operaciones ejercido por el franquiciador, el royalty podrá ser determinado de forma más eficiente. En cambio, cuando el control sea más difícil o resulte una tarea complicada y costosa, el franquiciador tenderá a establecer una cantidad fija en concepto de royalty, aunque ello no siempre resulte eficiente (Sashi y Karuppur, 2002). Es por esto que animamos a la propuesta de soluciones que permitan determinar mejor la cuantía del royalty en las franquicias de servicios.

Por último, queremos destacar el escaso número de trabajos que han estudiado la selección de mercados llevada a cabo por las cadenas franquiciadoras. Además, los pocos que lo han hecho, casi siempre se han centrado en el sistema de franquicia norteamericano y británico (véase, por ejemplo, Alon y McKee, 1999; Hoffman y Preble, 2001; Michael, 2003). Desde aquí, animamos a nuestros investigadores a cubrir este vacío en ambos frentes: análisis del tema y utilización de una muestra de datos pertenecientes al sistema de franquicia español.

\section{REFERENCIAS BIBLIOGRÁFICAS}

ALON, I. (2001): «The use of franchising by U.S. based retailers», Journal of Small Business Management, Vol. 32, No. 9, pp. 111-122

ALON, I. Y MCKEE, D. (1999): «Towards a macro environmental model of international franchising», Multinational Business Review, Vol. 7, No. 1, pp. 76-82

ALONSO, M. (1997): «Una franquicia para mi nuevo negocio», Ed. Selina Olmedo, Madrid.

ALONSO, M. (2003): «La franquicia de la "A" a la "Z". Manual para el franquiciador y el franquiciado», Ediciones Mariano Alonso y LID Editorial Empresarial, S.L. Madrid.

AQUINO, N. Y RONDÁN, F. J. (1999): «La franquicia en España: el sector de la hostelería-restauración y el sector de la confección-moda», XIII Congreso Nacional y IX Hispano-Francés, pp. 333-339

ARRIBAS, A. (1996): «La franquicia como forma de management sobre negocios de terceros», Tesis Doctoral de la Universidad Pontificia de Comillas.

BAENA, V. (2008): «La franquicia española: grado de internacionalización y formas de entrada», Tesis Doctoral de la Universidad de Alcalá.

BAENA, V. (2009): «Modeling global franchising in emerging markets. An entry mode analysis», Journal of East West Business, Vol. 15, No.3, pp. 164-188.

BAENA, V. Y CERVIÑO, J. (2008a): «Modeling international diffusion of franchising from a country level perspective», 50 a edición del Academy of International Business Annual Meeting, Milán, Italia, 30 de junio-3 de julio. 
BAENA, V. Y CERVIÑO, J. (2008b): «Forma de entrada de la franquicia española: franquicia directa, máster franquicia, joint venture e inversión directa», XX Encuentro de Profesores Universitarios de Marketing, Gran Canarias, 17-19 de septiembre.

BAENA, V. Y CERVIÑO, J. (2008c): «La franquicia española: el efecto de la experiencia, tipo de actividad y renombre de marca en su grado de internacionalización», XX Encuentro de Profesores Universitarios de Marketing, Gran Canarias, 17-19 de septiembre.

BAENA, V. Y CERVIÑO, J (2009): «La internacionalización de la franquicia española y sus formas de penetración de mercados», Cuadernos de Economía y Dirección de la Empresa, Vol. 40, pp. 47-82

BARREIROS, B. DÍEZ DE CASTRO, E. DÍEZ, J. T. RONDÁN F. J. Y SÁNCHEZ, M. J. (2004): «La elección del canal de distribución comercial», Editorial: MC Graw-Hill, Madrid.

BENAVIDES, M. C., MINGUETA, B. Y LÓPEZ J. I. (2008): «Transferencia de conocimiento en la creación y en el funcionamiento de los sistemas de franquicia. Un estudio empírico», Economía Industrial, Vol. 368, pp. 227-237

BERMEJO, M. (2002): «La franquicia: visión estratégica y tendencias de futuro», Harvard Deusto Marketing y Ventas, Vol. 50, pp. 42-45

BERMÚDEZ, G. (2001): «Satisfacción y fidelidad en la relación franquiciada franquiciador», Tesis Doctoral de la Universidad de Málaga

BERMÚDEZ G. (2002): «La franquicia: elementos, relaciones y estrategias», ESIC Editorial, Madrid

BERNI, F. (2002): «Corel values: keys to finding successful franchisees», Franchising World, Vol. 34 , No. 4 , pp. $15-17$

BOLEA DE ANTA, A. (1990): «Los grandes de la franquicia. El secreto de su éxito», Editorial: Ciencias Sociales, Madrid.

BORDONABA, M. (2003): «Determinantes del éxito de las relaciones comerciales a largo plazo entre empresas: análisis empírico en el sistema de franquicia», Tesis Doctoral de la Universidad de Zaragoza.

BORDONABA, V. Y POLO, Y. (2003): «Determinantes del éxito de las relaciones en el canal: semejanzas y diferencias en las perspectivas de un franquiciador y sus franquiciados», $X V E n$ cuentro de Profesores Universitarios de Marketing, Córdoba, 24-26 de septiembre.

BORDONABA, V., LUCIA, L. Y POLO, Y. (2008a): «Influencia de la duración y el grado de orientación relacional en la franquicia», Revista Española de Investigación de Marketing, Vol. 12, No. 1, pp. 7-25

BORDONABA, V., LUCIA, L. Y POLO, Y. (2008b): «Análisis del ciclo de vida de la franquicia en los sectores de moda y restauración», Universia Business Review, Vol. 19, No. 1, pp. 42-59

BORDONABA, V., LUCIA, L. Y POLO, Y. (2008c): «Análisis de la salida de mercado. Fracaso vs. abandono en la franquicia», Cuadernos de Economía y Dirección de la Empresa, Vol. 39, No. 1, pp. 33-58

BORDONABA, V., LUCIA, L. Y POLO, Y. (2008d): «Efectos directos y moderadores de la experiencia en la expansión de la franquicia: un análisis sectorial», XX Encuentro de Profesores Universitarios de Marketing, Gran Canarias, 17-19 de septiembre.

BORDONABA, V., LUCIA, L. Y POLO, Y. (2009): «Franchise firm entry time influence on longterm survival», International Journal of Retail \& Distribution Management, Vol. 37, No. 2, pp. 106-125.

BRICKLE, J. A. Y DARK, F. H. (1987): «The choice of organisational form: the case of franchising», Journal of Financial Economics, Vol. 18, pp. 401-420.

BURTON, F. CROSS, A. R. Y RHODES, M. (2000): «Foreign market servicing strategies of UK franchisors: An empirical enquiry from a transaction cost perspective», Management International Review, Vol. 40, No. 4, pp. 373-400.

CALDERÓN, E. (1998): «Los costes de la agencia en los canales de distribución: la franquicia», Tesis Doctoral de la Universidad de Burgos. 
CALDERÓN, E. (2000): «Los costes de supervisión y la decisión de franquiciar: el caso del sector servicios», X Jornadas Luso Españolas de Gestao, Vilamoura, 2-4 de febrero, pp. 315-326

CALDERÓN, E. (2002): «Factores determinantes de la decisión de franquiciar en las enseñas españolas», Cuadernos de Economía y Dirección de Empresa, Vol. 11, pp. 105-125

CARNEY, M. Y GEDAJLOVIC, E. (1991): «Vertical integration in franchise systems: agency theory and resource explanations», Strategic Management Journal, Vol. 12, pp. 607-629.

CASTROGIOVANNI, G. JUSTIS, R. Y JULIAN, S. (1993): «Franchise failures rates: an assessment of magnitude and influencing factors», Journal of Small Business Management, Vol. 12, pp. $105-114$

CASTROGIOVANNI, G. J., BENNET, N. Y COMBS, J. G. (1995); «Franchisor types: re-examination and clarification», Journal of Small Business Management, Vol. 33, No. 1, pp. 45-55.

CAVES, R. Y MURPHY, W. (1976): «Franchising: firms, markets, and intangible assets», Southern Economic Journal, Vol. 42, pp. 572-586

CERVIÑO, J. (1999): «La franquicia en los procesos de internacionalización empresarial», en Guía Práctica del Franquiciador - Tormo \& Asociados, Ed. Selina Olmedo, Madrid, pp. 171-177

CHANG, S. Y ROSENZWEIG, P. (2001): «The choice of entry mode in sequential foreign direct investment», Strategic Management Journal, Vol. 22, pp. 747-776

COASE, R. H (1937): «The nature of the firm», Económica, noviembre.

COMBS, J. G. Y CASTROGIOVANNI, G. J. (1994): «Franchisor strategy: a proposed model and empirical test of franchise versus company ownership», Journal of Small Business Management, Vol. 32, No. 2, pp. 37-48.

COMBS, J. G. Y KETCHEN, D. (1999): «Can capital scarcity help agency theory explain franchising? Revisiting the capital scarcity hypothesis», Academy of Management Journal, Vol. 42, No. 2, pp. 196-207

COMBS, J. G. Y KETCHEN, D. J. (2003): «Why do firms use franchising as an entrepreneurial strategy? A meta-analysis», Journal of management, Vol. 29, No. 3, pp. 443-465

CURZ, J. (2006): «El sistema de franquicia en la micro, pequeña y mediana empresas: (MiPyme). El caso venezolano», Tesis Doctoral de la Universidad de Málaga

DANT, R. Y KAUFMANN, P. (2003): «Structural and strategic dynamics in franchising», Journal of Retailing, Vol. 79, pp. 63-75.

DANT, R. KAUFMANN, P. Y PASWAN, A. (1996): «Ownership redirection in franchised channels», Journal of Public Policy and Marketing, Vol. 11, pp. 33-44

DANT, R., PERRIGOT, R. Y CLIQUET, G. (2008): «A cross-cultural comparison of the plural forms in franchise networks: United States, France and Brazil», Journal of Small Business Management, Vol. 46, No. 2, pp. 286-311

DECEGLIE, P. (1993): «What franchisor look for», Nation's Business, Vol. 81, No. 7, pp. 58.59

DÍAZ-BERNARDO, R. (2000): «Recursos y capacidades en el sistema de franquicia», Tesis doctoral, IESE, Universidad de Navarra.

DÍAZ-BERNARDO, R., INIESTA, F. P. Y NUENO, J. L. (1998): «La franquicia en España», Editorial: AECOC, Barcelona.

DÍEZ DE CASTRO, E. Y GALÁN, J. L. (1989): «El franchising: España y la CEE. Consideraciones legales», Investigación y Marketing, No. 30, pp. 31-42

DÍEZ DE CASTRO, E. Y GALÁN, J. L. (1998): «Práctica de la franquicia», Editorial: Mc GrawHill Interamericana de España, Madrid.

DÍEZ DE CASTRO, E. NAVARRO Y RONDÁN, F. C. (2005): «Strategic groups in the Spanish franchising system» en"Simultaneidad decisional y multifocalidad empresarial", pp. 257-270.

DÍEZ DE CASTRO, E. NAVARRO, A. Y RONDÁN, F. J. (2006a): «El sistema de franquicia. Una propuesta de un código de ética óptimo», X Coloquios Andaluces Sobre Temas Empresariales. Universidad de Córdoba, pp. 1-16. 
DÍEZ DE CASTRO, E. NAVARRO, A. Y RONDÁN, F. J. (2006b): «El Sistema de franquicia: investigación sobre el asociacionismo en el mundo. Competencia sin fronteras», Ed. La Coria. Trujillo.

DÍEZ DE CASTRO, E. RODRÍGUEZ, C, J. Y NAVARRO, A. (2007): «Unidades franquiciadas versus propias en el sistema de franquicia: una investigación empírica», en" Conocimiento, innovación y emprendedores: camino al futuro", Ayala, J. C. (coord.). Universidad de la Rioja.

DÍEZ DE CASTRO, E. Y RONDÁN, F. C. (2004): «La investigación sobre franquicia», Revista de Investigaciones Europeas de Dirección y Economía de la Empresa, Vol. 10, No. 3, pp. 71-96

ECHEBARRÍA, J. A. (1995): «El contrato de franquicia: delimitación y contenido de las relaciones internas», Tesis Doctoral de la Universidad de Valladolid

EDEN, F. SELF, D. Y GRIDER, D. (1976): «Franchisors describe the ideal franchisee», Journal of Small Business Management, Vol. 14, No. 3, pp. 39-47

ELANGO, B. (2007): «Are franchisors with international operations different from those who are domestic market oriented? » Journal of Small Business Management, Vol. 45, No. 2, pp. 179-193

ELANGO, B. Y FRIED, V. H. (1997): «Franchising research: a literature review and synthesis», Journal of Small Business Management, Vol. 35, No. 3, pp. 68-81.

EROGLU, S. (1992): «The internationalisation process of franchise systems: a conceptual model», International Marketing Review, Vol. 9, No. 5, pp. 19-30.

ERRAMILLI, M. K. AGARWAL, S. Y DEV, C. (2002): «Choice between non-equity entry modes: an organizational capability perspective», Journal of International Business Studies, Vol. 33, No. 2, pp. 223-243

FALBE, C. Y WELSH, D. (1998): «NAFTA and franchising: A comparison of franchisor perceptions of characteristics associated with franchisee success and failure in Canada, Mexico and the United States», Journal of Business Venturing, Vol. 13, No. 2, pp.151-171

FERNÁNDEZ, M. (2003): «Modelo de comportamiento de la organización Virtual. Una aplicación empírica a los sistemas de franquicia», Tesis Doctoral de la Universidad de Las Palmas de Gran Canaria.

FERNÁNDEZ, M. Y MARTÍN, J. (2006): «La confianza y el compromiso como factores clave de éxito en las relaciones comerciales. Una aplicación empírica en el sistema de franquicia», Revista Europea de Dirección y Economía de la Empresa, Vol. 15. No. 1, pp. 77-100.

FERNÁNDEZ, M. Y MELIÁN, L. (2005): «An analysis of quality management in franchise systems», European Journal of Marketing, Vol. 39, No. 5/6; pp. 585-608

FENWICK, G. Y STROMBOM, M. (1998): «The determinants of franchisee performance: an empirical investigation», International Small Business, Vol. 16, No. 4, pp. 28.45

FORWARD, J. Y FULOP, C. (1993): «Elements of a franchise: the experiences of established firms», The Service Industries Journal, Vol. 13, No. 4, pp. 159-178

GALLEGO, E. Y FERNÁNDEZ, L. (1991): «La franquicia», Ed: Trivium, Madrid.

GALINI, N. Y LUTZ, N. (1992): «Dual distribution and royalty fees in franchising», Journal of Law, Economics and Organization, Vol. 8, pp. 471-501.

GÁMEZ, J. (2009) «La ética en el sistema de franquicia», Tesis Doctoral de la Universidad de Sevilla

GÁMEZ, J., DÍEZ DE CASTRO, E., NAVARRO, A. Y RONDÁN, F. J. (2008): «C-40: propuesta de un modelo de código de ética en la franquicia», XX Encuentro de Profesores Universitarios de Marketing, Gran Canarias, 17-19 de septiembre.

GARCÍA, N. SANZO, M. J. Y TRESPALACIOS, J. A. (2004): «Condicionantes de la satisfacción en las relaciones en franquicias de servicios» Revista Europea de Dirección y Economía de la Empresa, Vol. 13, No. 1, pp. 101-114.

GARG, V. K. (2005): «An integrative approach to franchisors strategy in large chains», Journal of Applied Management and Entrepreneurship, Vol. 10, No. 2, pp. 58-74. 
GARG, V. K. Y RASHEED, A. (2006): «An explanation of international franchisor's preference for multi-unit franchising», International Journal of Entrepreneurship, Vol. 10, pp. 1-20

GINER, C. A. (1993): «El aprovisionamiento del franquiciado y derecho de la libre competencia», Tesis Doctoral de la Universidad Carlos III de Madrid

GUZMÁN, R. (1995): «La franquicia como estrategia para las Pymes», Tesis Doctoral de la Universidad de Málaga

HING, N. (1995): «Franchisee satisfaction: contributors and consequences», Journal of Small Business Management, Vol. 33, No. 2, pp. 12-23

HOFFMAN, R. Y PREBLE, J. (2001): «Global diffusion of franchising: A country level examination», Multinational Business Review, Vol. 9, No. 1, pp. 66-75.

HOFFMAN, R. Y PREBLE, J. (2004). «Global franchising: Current status and future challenges», The Journal of Services Marketing, Vol. 18, No. (2/3), pp. 101-114.

HOLMBERG, S. R. Y MORGAN, K. B. (2003): «Franchise turnover and failure. New research and perspectives», Journal of Business Venturing, Vol. 18, pp. 403-418

HUNT, S. D. (1972): «The trend toward company-operated units in franchise chains», Journal of Retailing, Vol. 49, pp. 110-119

JENSEN, M. C. Y MECKLING, W. H. (1976): «Theory of the firm: managerial behaviour, agency costs and ownership structure», Journal of Financial Economics, Vol. 3, pp. 305-360

JIMENEZ, D. (2006): «Modelo de decisión multicriterio aplicado al emplazamiento de "cofee shops" en el levante español: sinergia y canibalismo entre la franquicia y el corner como negocios complementarios», Tesis Doctoral de la Universidad San Pablo-CEU

KASSELMANN, B. DE BEER, J. Y VERMEULEN, L. (2002): «Personality attributes of successful franchisees in the fast foods sector in South Africa», South African Journal of Economic and Management Sciences, Vol. 5, No. 1, pp. 154-179

KAUFMANN, P. Y STANWORTH, J. (1995): «The decision to purchase a franchise: a study of prospective franchisees», Journal of Small Business Management, Vol. 33, No. 4, pp. 22-32

KNIGHT, R. (1986): «Franchising from the franchisor and franchisee points of view», Journal of Small Business Management, Vol. 24, No. 3, pp. 8-15

LAFONTAINE, F. (1993): «Contractual arrangement as signalling devices: evidence from franchising», Journal of Law, Economics and Organization, Vol. 9, No. 2, pp. 256-289

LAFONTAINE, F. Y SHAW, K. L. (1999): «The dynamics of franchise contracting: evidence from panel data», The Journal of Political Economy, Vol. 107, No. 5. pp. 1041-1080.

LÓPEZ, M.B. (1999): «Los acuerdo de franquicia: análisis de la racionalidad económica en el proceso de creación, transmisión y protección del conocimiento organizativo», Tesis Doctoral de la Universidad de Oviedo

LÓPEZ, M. B. Y GONZÁLEZ, M. (2001a): «El proceso de internacionalización de la franquicia española», XI Congreso Nacional de ACEDE

LÓPEZ, M. B. Y GONZÁLEZ, M. (2001b): «El proceso de internacionalización de la franquicia española», ICADE: Revista de las Facultades de Derecho y Ciencias Económicas y Empresariales, Vol. 54, pp. 237-256

LÓPEZ, M. B. Y VENTURA, J. (2001): «Grupos estratégicos en las franquicias españolas», Economía Industrial, Vol. 34, pp. 163-196

LÓPEZ, M. B. Y VENTURA, J. (2002): «Integración vertical y costes de aparición de la franquicia», Revista Europea de Dirección y Economía de la Empresa, Vol. 11, No. 4, pp. 55-74

LUCIA, L. (2008): «Decisiones de entrada y salida del mercado: un análisis empírico aplicado al sistema de franquicia español», Tesis Doctoral de la Universidad de Zaragoza

MARIZ, R. M. (2007): «Análisis de la evolución de las cadenas de establecimientos franquiciados. Una visión dinámica de los condicionantes de la estructura de propiedad de las enseñas españolas», Tesis Doctoral de la Universidad A Coruña 
MARIZ, R. M. GARCÍA, M. T. Y CALVO, N. (2004): «El crecimiento de las cadenas de franquicias: un análisis empírico desde el enfoque de la teoría de la agencia», XVIII Congreso anual AEDEM, Orense.

MARTI, J. (2009): «El contrato de máster franquicia», Tesis Doctoral de la Universitat de Valencia

MARTÍN, J. D. FERNÁNDEZ, M. Y BEERLI, A. (2005): «La comunicación y la confianza como determinantes del resultado en los sistemas de franquicia» XVII Encuentro de profesores universitarios de marketing, Madrid, 22-23 de septiembre.

MARTÍNEZ, F. J. (1994a): «Qué es una franquicia?», Actualidad Financiera, Vol. 2, No. 1, pp. 341-348

MARTÍNEZ, F. J. (1994b): «Legislación y contabilidad para la franquicia», Actualidad Financiera, Vol. 2, No. 1, pp. 349-355

MARTÍNEZ, F. J. (1994c): «Franquicia o establecimiento propio», Actualidad Financiera, Vol. 2, No. 1, pp. 357-365

MARTÍNEZ, F. J. (1994d): «La financiación de un proyecto de franquicia», Actualidad Financiera, Vol. 2, No. 1, pp. 375-378

MARTÍNEZ, F. J. (1994e): «La franquicia y su situación en los mercados internacionales», Actualidad Financiera, Vol. 2, No. 1, pp. 389-398

MAURICIO, S. (1994): «La franquicia sobre el consumo en canarias. Análisis histórico y regimen actual», Tesis Doctoral de la Universidad de Las Palmas de Gran Canaria

MAYORGA, M. C. (2002): «Régimen jurídico del contrato de franquicia», Tesis Doctoral de la Universidad de Málaga

MICHAEL, S. C. (2003): «Determinants of the rate of franchising among nations», Management International Review, Vol. 43, No. 3; pp. 267-291

MICHAEL, S. (2009): «Entrepreneurial signalling to attract resources: the case of franchising», Managerial and Decision Economics, Vol. 30, pp. 405-422

MONTSERRAT, J. M. (2005): «Sistemas y procesos de comunicación organizacional en las empresas franquiciadoras: creación de un modelo de optimización de la eficacia», Tesis Doctoral de la Universidad Cardenal Herrera - CEU

MORO, M.A. (1999): «Análisis económico y contable de la franquicia como estrategia de supervivencia y expansión en los mercados», Tesis Doctoral de la Universidad de Oviedo

MORO, M. A. (2002): «Teorías que justifican el uso de la franquicia: contraste empírico», Revista de Economía y Empresa, Vol.XVII.

MÚGICA, J. M. Y YAGÜE, M. J. (1996): «Franquicias internacionales», Papeles de economía española, No. 66, pp. 267-280

NAVARRO, A. DÍEZ DE CASTRO, E. Y RONDÁN, F. (2005): «Estrategias y tipos de franquiciadores en el sistema de franquicia español», XVII Encuentro de Profesores Universitarios de Marketing, Madrid, 22-23 de septiembre.

NAVARRO, A., DÍEZ DE CASTRO, E., RONDÁN, F. J. Y DÍEZ, F. (2005): «El Sistema de franquicia: fundamentos teóricos y prácticos», Ed. Pirámide, Madrid.

NAVARRO, A, DÍEZ DE CASTRO, E. Y RONDÁN, F. J. (2006): «Franchisor types in Portuguese franchising», The Portuguese Journal of Management Studies, Vol. 11, No. 2, pp. 97-114

NAVARRO, A, RONDAN F. J. Y DÍEZ DE CASTRO, E. (2005): «Grouping franchisors types», $4^{\text {th }}$ International Conference of the Iberoamerican Academy of Management, Lisboa, 8-11 diciembre.

PADILLA, N. (2002): «Cómo seleccionar una franquicia mediante AHP» XVI Congresos de AEDEM, Alicante, 4-7 de junio.

PALACIOS, L. POLO, Y. Y BORDONABA, M. V. (2005): «Relevancia del momento de entrada en la franquicia. Un estudio empírico a partir del análisis de supervivencia», XVII Encuentro de profesores universitarios de marketing, Madrid, 22-23 de septiembre. 
PERALES, N. (1999): «Las cadenas de franquicia como una forma de organización plural», Tesis Doctoral de la Universidad Complutense de Madrid

OXENFELDT, A. R. Y KELLY, A. O. (1969): «Hill successful franchise systems ultimately become wholly owned chains?, Journal of Retailing, Vol. 44, No. 4, pp. 69-83

QUINN, B. Y DOHERTY, A. M. (2000): «Power and control in international retail franchising. Evidence from theory and practice», International Marketing Review, Vol. 17, No. 4/5, pp. 354-371.

RAMÍREZ, J. M. (2005): «Una primera aproximación sobre los criterios utilizados por los franquiciados en la selección de una enseña franquiciadora», XIXC Reunión Anual Asepelt, Badajoz.

RAMÍREZ, J. M. (2007): «Determinación y estudio del perfil de franquiciado mediante la aplicación de análisis conjunto», Tesis Doctoral de la Universidad Pablo de Olavide.

RAMÍREZ, J. M. BERBEL, J. M. Y BARRERA, R. (2007): «Radiografía de las empresas cerveceras que operan bajo el sistema de franquicia en España», en"Conocimiento, innovación y emprendedores: camino al futuro, Ayala, J. C. (coord.). Universidad de la Rioja. Servicio de Publicaciones.

RAMÍREZ, J. GUERRERO, F. Y RONDÁN, F. (2005): «Algunas consideraciones sobre los criterios básicos utilizados por los franquiciados en la selección de una enseña franquiciadora», Revista de Economía y Empresa, Vol. XXIII, No. 54/55, pp. 51-68

RAMÍREZ, J. GUERRERO, F. Y RONDÁN, F. J. (2006): «Utilización del análisis conjunto para el estudio de las preferencias de los franquiciadores sobre el perfil de franquiciado», Estudios de Economía Aplicada, Vol. 24, No. 3, pp. 979-1012

RAMÍREZ, J. GUERRERO, F. RONDÁN, F. J. BERBEL, J. M. Y BARRERA, R. (2006): «Identification of the profile of franchisee preferred by the franchisors that operate in the Spanish market», $5^{\text {th }}$ International Congress Marketing Trends, Venecia.

RAMÍREZ, J., RONDÁN, F. J. Y DÍEZ DE CASTRO, E. (2007): «Tipologías de franquiciadores a través del análisis clúster», en"Conocimiento, innovación y emprendedores: camino al futuro“, Ayala, J. C. (coord.). Universidad de la Rioja. Servicio de Publicaciones. pp. 1987-1999. XVII Jornadas Hispano-Lusas de Gestión Científica.

RAMÍREZ, J. RONDÁN, F. Y GUERRERO, F. (2007): «Selección de franquiciados mediante simulación con análisis conjunto», Cuadernos de Economía y Dirección de la Empresa, Vol. 31, pp. $171-202$

RAMÍREZ, J. GUERRERO, F. Y RONDÁN, F. (2005): «Algunas consideraciones sobre los criterios básicos utilizados por los franquiciados en la selección de una enseña franquiciadora», Revista de Economía y Empresa, Vol. XXIII, No. 54/55, pp. 51-68

RIBEIRO, D. (2003): «The Impact of Consulting Service on Spanish Firms» Journal of Small Business Management, Vol. 41, No. 4, pp. 409-416.

RIBEIRO, D. (2005): «Franchising in Spain: Agency and capital scarcity perspectives», The Service Industries Journal, Vol.25, No. 8, pp. 1015-1027

RIBEIRO, D. Y RIBES, A. (2000): «El mercado de la franquicia española: Necesidad de valores culturales», Boletín Económico de Información Comercial Española, Vol. 2648, pp. 9-19.

RIGOL, J. (1989): «La franquicia; una estrategia de expansión para la empresa», Tesis Doctoral de la Universidad de Barcelona

RODRÍGUEZ, M. C. (2007): «Factores condicionantes de la transferencia de conocimiento. Un estudio empírico de sus influencias en el rendimiento de los sistemas de franquicia», Tesis Doctoral de la Universidad Complutense de Madrid

RODRIGUEZ, M. C. MINGUELA, B. Y LÓPEZ, J. I. (2008): «Transferencia de conocimiento en la creación y en el funcionamiento de los sistemas de franquicia: un estudio empírico», Economía Industrial, Vol. 368, pp. 227-237

RODRIGUES, P. (2002): «Medida del éxito en una red de franquicia: estructura y comportamiento versus performance», Tesis Doctoral de la Universidad Complutense de Madrid 
RONDÁN, F. J. Y DÍEZ DE CASTRO, E. C. (2004): «La Investigación sobre franquicia», Investigaciones Europeas de Dirección y Economía de la Empresa, Vol. 10. No. 3, pp. 71-96

RONDÁN F. J. DÍEZ DE CASTRO, E. Y NAVARRO, A. (2006a): «Strategic groups: the case of the Spanish franchising», $5^{\text {th }}$ International Congress Marketing Trends.

RONDÁN F. J. DÍEZ DE CASTRO, E. Y NAVARRO, A. (2006a): «Strategic groups: the case of the Spanish franchising», $5^{\text {th }}$ International Congress Marketing Trends.

RONDÁN, F. J. DÍEZ DE CASTRO, E. C. Y NAVARRO, A. (2006b): «La responsabilidad social corporativa: análisis mundial del Asociacionismo en el sistema de franquicia. Los límites de la responsabilidad social de la empresa», AEDEM, pp. 183-198.

RONDÁN, F. J. DÍEZ DE CASTRO, E. C. RODRÍGUEZ, C. J. Y NAVARRO, A. (2008): «razones para la expansión en franquicia: una investigación mediante regresión de clases latentes», $X X$ Encuentro de Profesores Universitarios de Marketing, Gran Canarias, 17-19 de septiembre.

RONDÁN, F. J. NAVARRO, A. Y DÍEZ DE CASTRO, E. C. (2006): «Grupos estratégicos en el sistema de franquicia: el caso de España y Portugal. Decisiones basadas en el conocimiento y en el papel social de la empresa» AEDEM, Vigo, pp. 460-470.

RONDÁN, F. J. NAVARRO, A. Y DÍEZ DE CASTRO, E. (2007): «¿Es la franquicia un sistema dual», en "Conocimiento, innovación y emprendedores: camino al futuro", Ayala, J. C. (coord.), XVII Jornadas Hispano Lusas de Gestión Científica. 8 y 9 de febrero.

RODRÍGUEZ, C. J. Y NAVARRO, A. (2007): «Una investigación sobre el fracaso de los franquiciadores en España», en" Conocimiento, innovación y emprendedores: camino al futuro", Ayala, J. C. (coord.). Universidad de la Rioja. Servicio de Publicaciones.

RONDÁN, F. J. NAVARRO, A. Y DÍEZ DE CASTRO, E. C. (2006): «Grupos estratégicos en el sistema de franquicia: el caso de España y Portugal. Decisiones basadas en el conocimiento y en el papel social de la empresa», AEDEM, pp. 460-470.

RONDÁN, F. J. NAVARRO, A. Y DÍEZ DE CASTRO, E. (2007): «¿Es la franquicia un sistema dual?», en"Conocimiento, innovación y emprendedores: camino al futuro", Ayala, J. C. (coord.). Universidad de la Rioja. Servicio de Publicaciones, pp. 2157-2173. XVII Jornadas Hispano Lusas de Gestión Científica, 8 y 9 de febrero de 2007.

RYANS, J. LOTZ, S. Y KRAMPF, R. (1999): «Do master franchisors drive global franchising?», Marketing Management, Vol. 8, No. 2, pp. 32-37.

RUIZ, J. I. (1991): «El contrato de franquicia y las nuevas normas de defensa de la competencia», Ed. Cívitas, Madrid.

SÁNCHEZ, J. (2005): «La extinción del contrato de franquicia y sus consecuencias», Tesis Doctoral de la Universidad Cardenal Herrera - $C E U$

SÁNCHEZ, E. Y PLA, J. (2004): «Una concepción multidimensional de la incertidumbre y su influencia en el método de expansión internacional: el rol de la innovación en el sector servicios», Cuadernos de Economía y Dirección de la Empresa, Vol. 20, pp. 131-150

SÁNCHEZ, E. Y PLA, J. (2006): «Un enfoque integrador de la elección del modo de entrada en los mercados internacionales. Una aproximación empírica en sectores de servicios», Management International, Vol. 10, No. 2, pp. 43-23.

SANCHO, A. (2000): «El canon de entrada versus la calidad percibida de la enseña» Tesis Doctoral de la Universidad Europea de Madrid.

SASHI, C. M. Y KARUPPUR, D. P. (2002): «Franchising in global markets: towards a conceptual framework», International Business Review, Vol. 19, No. 4/5, pp. 499-524.

SHANE, S. (1996): «Why franchise companies expand overseas», Journal of Business Venturing, Vol. 11, No. 2, pp.73-88.

SHANE, S. (1998): «Making new franchise systems work», Strategic Management Journal, Vol.19, No. 7, pp. 697-707.

SHANE, S., SHANKAR, V. Y ARAVIDAKSHAN, A. (2006): «The effects of new franchisors partnering strategies on franchise system size», Management Science, Vol. 52, No. pp. 773-787. 
SIGUÉ, S. P. Y REBOLLEDO, C. (2004): «La franquicia en Colombia: ¿una alternativa a la escasez de recursos o una opción para aumentar la eficiencia?», Management International, Vol. 8, No. 2; pp. 15- 24.

SOLIS, V. (2009): «Incentivos, financiación y diseño contractual en la gestión de cadenas de franquicia», Tesis Doctoral de la Universidad de Oviedo

SOLÍS, V. Y GONZÁLEZ, M. (2007): «La franquicia como estrategia de crecimiento de las PYMES españolas», en”Conocimiento, innovación y emprendedores: camino al futuro“, Ayala, J. C. (coord.). Universidad de la Rioja.

SOLÍS, V. Y GONZÁLEZ, M. (2008): «La forma plural de la franquicia española: estructura y evolución», Revista Europea de dirección y economía de la empresa, Vol. 17, № 2, pp. 105-122.

TATHAM, R. DOUGLAS, R. Y BUSH, R. (1972): «An analysis of decision criteria in franchisor/ franchisee selection processes», Journal of Retailing, Vol. 48, No. 1, pp. 16.22

TORMO, E. (2002): «¿Por qué franquician las empresas?», Harvard Deusto Marketing y Ventas, No. 50 , pp. 36-40

TORMO \& ASOCIADOS (2008): «Guía de Franquicias y Oportunidades de Negocio», Editoral Selina Olmedo, Madrid.

VÁZQUEZ, L. (1998) «La eficiencia organizativa de la franquicia en la comercialización de automóviles», Tesis Doctoral de la Universidad de Oviedo

WATSON, A. KIRBY, D. Y EGAN, J. (2002): «Franchising, retailing and the development of ecommerce», International Journal of Retailing \& Distribution Management, Vol. 30, No. 5, pp. 228-237

WELSH, D. ALON, I. Y FALBE, C. (2006): «An examination of international retail franchising in emerging markets», Journal of Small Business Management, Vol. 44, No. 1, pp. 130-150

WILLIAMSON, O. E. (1975): «Markets and Hierarchies: Analysis and antitrust implications», Editorial: Free Press, New York.

WINDSPERGER, J. (2001): «The fee structure in franchising: a property rights view», Economics Letters, Vol. 73, No. 2, pp. 219-226

WITHANE, S. (1991): «Franchising and franchisee: an examination of opinions, personal characteristics and motives of Canadian franchisee entrepreneurs», Journal of Small Business Management, Vol. 29, No. 1, pp. 22-29

ZOU, S. TAYLOR, C. R. Y CAVUSGIL, S. T. (2005): «The political economy explanation international market entry mode choice: an exploratory study» en "Handbook of research in International Marketing”, Jain, S. C. (eds.), Edward Elgar Publishing, Inc. Massachusetts, pp. 134-148 


\section{ANEXO}

Tabla 3

\section{Ordenación Sectorial del Sistema de Franquicia Español}

\begin{tabular}{|c|c|c|c|}
\hline 1 & Agencias Inmobiliarias & 27 & Moda Infantil y Juvenil \\
\hline 2 & Alimentación & 28 & Moda Lencería \\
\hline 3 & Belleza y cuidado personal & 29 & Moda Varios \\
\hline 4 & Centros de Estética y Belleza & 30 & Ocio \\
\hline 5 & Clínicas Odontológicas & 31 & Oficina y Papelería \\
\hline 6 & Compra/Venta de Artículos Usados & 32 & Óptica \\
\hline 7 & Comunicación, Internet y Telefonía & 33 & Panadería y Pastelería \\
\hline 8 & Consultoría y Servicios de Asesoramiento & 34 & Parafarmacia \\
\hline 9 & Cosmética & 35 & Peluquería \\
\hline 10 & Dietética y Herboristería & 36 & Producto Especializado \\
\hline 11 & Enseñanza & 37 & Publicidad y Comunicación \\
\hline 12 & Fotografía & 38 & Reciclaje y Consumibles \\
\hline 13 & Hotelería y Restauración: cafetería & 39 & Relaciones Personales \\
\hline 14 & Hotelería y Restauración: cervecería & 40 & Servicio a Domicilio \\
\hline 15 & Hotelería y Restauración: fast food & 41 & Servicio de Automóviles \\
\hline 16 & Hotelería y Restauración: heladería & 42 & Servicio de Transporte \\
\hline 17 & Hotelería y Restauración: tapas & 43 & Servicio Especializado \\
\hline 18 & Hotelería y Restauración: temático & 44 & Servicio Financiero \\
\hline 19 & Hotelería y Restauración: varios & 45 & Textil, Regalo y Decoración Hogar \\
\hline 20 & Informática & 46 & Tienda de Vinos \\
\hline 21 & Joyería y Bisutería & 47 & Tienda Deportes \\
\hline 22 & Juguetería & 48 & Tienda Especializada \\
\hline 23 & Mobiliario & 49 & Tintorería/Lavandería \\
\hline 24 & Moda Caballeros y Camisería & 50 & Vending \\
\hline 25 & Moda Complementos & 51 & Viajes \\
\hline 26 & Moda Femenina & 52 & Videocajeros y Videoclub \\
\hline
\end{tabular}

Fuente: Elaboración propia a partir de la clasificación publicada en Tormo \& Asociados (2008) 